\title{
How a Personal Brand that has been Creatively Established in Social Media Becomes a Passport to Traditional Media and Receiving Advertising Contracts
}

\author{
Mateusz Grzesiak \\ Starway Institute \\ Ogrodowa Street 58 (City Gate), 00-876 Warsaw, Poland \\ mg@starwayinstitute.com
}

\begin{abstract}
YouTube is one of the most effective instruments for shaping personal brand among members of the young generation (generations $\mathrm{Y}$ and $\mathrm{Z}$ ). The goal of the paper is to show the process of establishing personal brand in social media as well as showing how popularity in social media influences receiving advertising contracts. In the paper following assumption has been made: owing the creative ideas and their appropriate realization, people creating their content on YouTube may establish cooperation with brands in the scope of advertising (through publishing promotional materials on their channel or by product placement) as well as reviewing (through reviewing particular products sent by producers). On the one hand, it enables gaining income and on the other hand, it facilitates increasing the scope and reaching new audience. The following research methods were applied for the purpose of implementation of assumed goal: critical analysis of the literature of the subject, results of own research method conducted in 2016 on the Polish and American market, case study method.
\end{abstract}

Keywords: Social Media, personal branding, YouTube, traditional media, communications

\section{Introduction}

Over the last decade, since May 2005 when former PayPal's employees Chad Hurley, Steve Chen and Jawed Karim did a public launch of the first version of YouTube, until now, channels with short videos have stopped being considered as only entertainment. Although entertainment is still the most popular content, for quite some time YouTube has been considered as one of the most effective tools for influencing and shaping the tastes of viewers and, what is most important from the viewpoint of the subject of this study, for personal branding [1].

One of the reasons for studying personal branding is the increasing connection between possible advertising revenues or the prospect of finding a good job and one's personal brand developed with the use of YouTube. This subject of this study are issues related to building and monetisation of a personal brand, in particular YouTube personal branding tools and the results of their use.

The importance of this research is twofold. First, there is a need for research that presents successful, effective, and clear messaging in online communities. Second, with YouTube's creation in 2005, its relevance to popular culture has grown, with over 1 billion users worldwide (YouTube 2016) [2].

\section{Young Generation Characteristics}

"Y" generation is a generation of people born in Poland between 1986 and 2010, and in other countries, like for example in the USA, they are the generation of population boom of the $80 \mathrm{~s}$ and 90 s of the twentieth century. They are also called "Millennium generation", "next generation", "digital generation" and the "generation of flip-flops and iPods". Technology M2M [machine to machine] is an active communication between the devices ["machines"]. It takes place via wireless or wired connection. M2M is usually identified with data transmission in GSM networks. M2M communication is a solution that consists in connecting devices to the outside world so that they can communicate with people and with each other. Connected devices not only provide information for their owners or third parties but they can also be controlled remotely, which provides many opportunities for companies and their customers [3]. This notion occurred for the first time in 1993, in "AD Age" magazine. Unlike the previous generation, referred to as Generation "X", they have "tamed" 
technological innovations and actively apply digital media and digital technologies; they are considered to be audacious generation that is open to new challenges.

On the other hand, the "Z" generation are people born after 1990, or - according to some experts - even after 1995. In general view they are most distinguished by the fact that new technologies are something ordinary and of daily use for them as they have been present in their life since their birth. They are also often referred to as "C" Generation - from the English word "Connected", meaning connected to the network. Experts place the word "change" at the basis of the definition of the generation; change as the situation they like most because continuous experimenting lets them develop themselves and offers a lot of experiences [4]. Representatives of the "Z" generation approach life in a realistic and materialistic way, but at the same time they tend to be creative and ambitious. They want to have and achieve everything immediately. They are also distinguished by their attitude to knowledge - they acquire it from the Internet, and therefore for them it is not a fundamental attribute of an employee in the labour market. The speed of finding information and creative approach to ways of reaching the information is more important.

\section{Characteristics of the Research Process}

An empirical study was conducted of personal branding strategies used by young people in Poland and in the United States. To the author's knowledge, at the time when the research was conducted, it was the first study in Poland or in the US covering that subject and sample. The research was conducted in 2016. The entire research process was conducted by the author of this own study.

The aim of the study was to gather information on attitudes and behaviour of young people (18-34 years old) with regard to personal branding in social media, in particular on YouTube.

The research involved two stages. First, exploratory qualitative research (case studies) was conducted, followed by quantitative research.

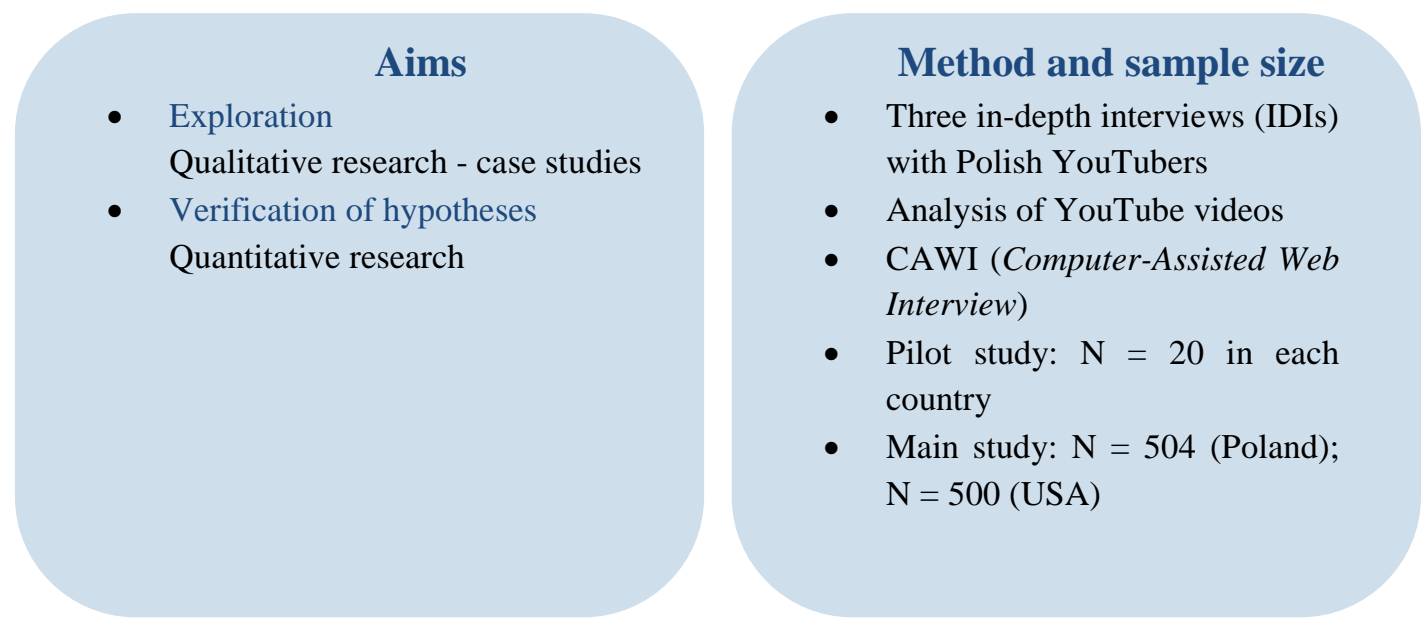

Fig. 1: Research overview.

In the paper selected results of the study are presented.

\section{Findings}

The major purpose of the survey of the Polish and American young people was to identify awareness and spontaneous understanding of the "personal branding" term.

45\% of young Poles and 55\% of young Americans have heard the term "personal brand". The term evokes a very broad set of concepts, but a very large number of people spoke spontaneously of building an appropriate image through social media. 52\% of Poles and 67\% of Americans have come across the term "personal brand" as defined by the author of this study. 
Another research research problem regarded personal branding activity. The study shows that, less than one fourth of the interviewees in each of the countries stated that they have been building their personal brand as defined in this study. A significant percentage ( $40 \%$ of Poles and $24 \%$ of Americans) have engaged in activities that build their personal brand but have not been aware that such activities are considered brand building.

Among Polish and American young people we can find following personal branding goals that are shown in the table 1.

Table 1: Personal branding goals - research results.

\begin{tabular}{|l|l|l|}
\hline Personal branding goals & \% answers in Poland & \% answers in USA \\
\hline Good image in the eyes of others & $\mathbf{1 6}$ & 39 \\
\hline Promotion, pay rise, getting job, business success & $\mathbf{1 5}$ & $\mathbf{2 3}$ \\
\hline Own satisfaction & $\mathbf{1 3}$ & $\mathbf{1}$ \\
\hline Meeting set goals, being succesful & $\mathbf{1 0}$ & $\mathbf{1 0}$ \\
\hline Respect of others, renown, admiration & $\mathbf{6}$ & $\mathbf{6}$ \\
\hline Being popular/making friends & $\mathbf{5}$ & $\mathbf{3}$ \\
\hline Personal development, gaining experience & $\mathbf{4}$ & $\mathbf{1}$ \\
\hline Popularity, fame, becoming recognizable & $\mathbf{3}$ & $\mathbf{4}$ \\
\hline Showing once's "true self" to the world & $\mathbf{1}$ & $\mathbf{4}$ \\
\hline Difficult to say & $\mathbf{3}$ & $\mathbf{4}$ \\
\hline Nothing & $\mathbf{5}$ & $\mathbf{2}$ \\
\hline
\end{tabular}

Among most important goals of personal branding polish and American young people have shown good image in the eyes of others. Also promotion, pay rise, getting job and business is important personal branding goal. There is a big difference in answers between polish and american respondents regarding own satisfaction.

Young people use different personal branding methods. Taking into consideration the results of the study, we can state that the method most frequently cited by the interviewees was posting on social media.

Facebook was the leading medium in both countries (among people engaged in personal branding, 86\% of Poles and $77 \%$ of Americans used Facebook). YouTube was used by $30 \%$ of Poles and 25\% of Americans. YouTube was the second most popular medium in Poland and the sixth most popular medium in the US (after Instagram, LinkedIn, Twitter, and Snapchat).

In both countries, Facebook was named as the most effective medium (by 56\% of Poles and 32\% of Americans). YouTube was named as the most effective medium by approx. $20 \%$ of the interviewees in both countries.

The most common personal branding activity on YouTube is, naturally, the recording and posting videos. It appears, however, that for a significant percentage of interviewees (19\% in both countries), YouTube is also a source of inspiration and knowledge. YouTube's advantages in that regard include its wide range (named by $27 \%$ of Poles and $16 \%$ of Americans engaged in personal branding on YouTube), the ability to show off one's advantages (21\% of Americans), and the fact that videos are an attractive and contemporary means of communication (16\% of Americans). It should be underlined, that YouTube is mainly considered a medium that facilitates financial and professional/educational success.

Over $80 \%$ of the interviewees in both countries are aware that YouTube presence can generate revenues. 50\% to $60 \%$ of the interviewees in both countries believe that one can make good money on YouTube.

The most popular YouTubers in the world are already making millions of dollars through their activity on their own YouTube channel alone, thanks to advertisements displayed next to the videos. 
Felix Kjellberg, the owner of the YouTube PewDiePie channel, is currently the highest earning YouTuber in the world. In 2014, he earned USD $7.4 \mathrm{~m}$ on ads displayed next to his videos, in 2015, that figure increased to USD $12 \mathrm{~m}$. He owes his success to playing video games and making video game-related movies. He comments on numerous releases on his channel, using funny, and often vulgar, vocabulary. His channel was established in April 2010 and since then, his videos have had more than nine billion views. Currently, PewDiePie has more than 43 million subscribers. Mr Kjellberg takes care to protect his privacy, avoiding interviews and conferences and rarely appearing at YouTube studios in California.[7]

Smosh is a duo of Ian Hecox and Anthony Padilla, two childhood friends who currently together run as many as five channels on YouTube. On those channels, they show their own comedy sketches, several months ago they made a featurelength Smosh: The Movie. They have made USD 8.5m through their YouTube activity, which makes them as successful in financial terms as the Fine Brothers.[8]

The Fine Brothers are brothers Benny and Rafi Fine, who became popular thanks to a series of videos showing people's reactions to YouTube videos such as the videos of the above mentioned PewDiePie videos or music videos by Nicki Minaj. Their online success inspired the Fine Brothers and Nick Cannon to make the React to That show, which is aired on the Nickelodeon children's TV channel. The Fine Brothers have nearly 14 million subscribers and have made USD $8.5 \mathrm{~m}$ through their YouTube channel.

Lindsey Stirling owes popularity to her uncommon talent, as she can play the violin while dancing. When her skills were not appreciated by recording companies, she decided to create a YouTube channel. Since 2007, she has reached 7.8 million subscribers and earned USD $6 \mathrm{~m}$ from ads in the last year. [9]

Rhett \& Link, that is Rhett McLaughlin and Charles Lincoln Neal III, are among the oldest best earning YouTubers at 38 and 37 years old, respectively. They both graduated from the NC State University and have worked at US corporations for many years. They became popular thanks to their parodies of morning TV news on their Good Mythical Morning channel. Last year, they earned USD $4.5 \mathrm{~m}$ through their YouTube channel (as they advertised brands such as Gillette, Toyota or Wendy's through their channel) [10].

KSI, or Olajide Olatunji, began his Internet career similarly to PewDiePie, commenting on video games on his gaming channel. He has, however, decided to cash in on his popularity by starting a music career. In April 2015, his hip-hop single Lamborghini made the UK Charts Top 40. In September 2016, KSI had over 11 million subscribers and made USD 4.5m on his YouTube channel.[11]

Channels specialising in make-up, haircuts and clothes make up the majority of popular YouTube videos. Michelle Phan, who became famous through demonstrating celebrity-like makeup to women, is currently the most popular YouTuber in that category. She earns some three million USD a year from her videos. She earns not only from her videos, but also from her own cosmetics and nails brands. She invests nearly all her earnings in her enterprises.

Lilly Singh, or IISuperwomanII on YouTube, is a comedian specialising in stand-up comedy strongly based on her Indian background. Ms Singh also sings - in 2015, she visited 27 cities on her global „A Trip to Unicorn Island” tour. Her YouTube revenues are estimated at USD 2.5m [12].

Roman Atwood is a YouTuber who specialises in prank videos, similar in concept to those by the Polish YouTuber Sylwester Wardęga. Mr Atwood became famous through his outlandish pranks such as scaring beachgoers with a fake skunk. His exploits earned him over 7 million subscribers and yearly revenues estimated at USD 2.5m [13].

Rosanna Pansino has a YouTube channel with cooking and baking videos. In 2015, she also published The Nerdy Nummies Cookbook: Sweet Treats for the Geek in All of Us. Ms Pansino makes money, among others, from her deal with Wilton Brands, producer of pans and bakeware. Her YouTube channel has 5.9 million subscribers, which brings her an estimated USD $2.5 \mathrm{~m}$ in revenues [14].

List of good practices - recommendations for developing personal brand (based on research results)

The research conclusions and the scope of this study allowed the author to prepare a list of behavior, activities and features required for maximizing [5] efficient personal branding on YouTube. The list of recommendations is provided below.

\section{Interactivity}

Keep in touch with your YouTube channel viewers by reacting to the requests and questions in their comments. Talk to your subscribers, even if they criticize the quality or content of the channel, and customize your message to meet, to the fullest possible extent, the specific expectations of the target audience.

\section{Engage with other YouTubers}


Engage with other YouTubers to record videos together or participate in the same promotional activities. This will increase the reach of your communications and the awareness of your channel by attracting the attention of other YouTuber's viewers and subscribers.

\section{Maintain a predictable format}

Your content's form should be profiled so that it is predictable to your subscribers. It should be clearly laid out and ought to fit into one of the familiar channel formats. Consequently, your viewers will always know what type of content and form they can expect in your videos. Such predictability makes it easier for the viewer to decide whether to subscribe and regularly visit your channel.

\section{Be consistent}

Always post new content regularly, at the same time and day, for example once a week on Mondays at 17:00. A lack of consistency in posting content, such as varying the times or frequency of posts, will result in lost viewers and fewer subscriptions.

\section{Have a unique persona}

Create and consistently maintain a unique persona that is easy for viewers to remember and distinguish from other personal brands. A unique persona is usually established through the use of specific clothes, employing unique and recognizable language for your message, behaviour (including body language), and manner of communication [6]. The more precise and consistent the persona in your videos, the more memorable it is for viewers and the more distinguishable it is from others.

\section{Maintain presence on multiple channels}

Be present on and use the communication opportunities of other social media (such as Facebook, Instagram, Snapchat, or LinkedIn) by posting content with links to your YouTube channel that will result in an increased range of communication and attract viewers as yet unfamiliar with your YouTube channel.

\section{Profile your target group}

Define the target group for your content precisely in terms of demographic and psychographic profile and match the form and content of your message as closely as possible to their needs. A message that does not meet the above requirement will confuse your viewers and lead to uncertainty whether they are the intended target for the message.

\section{Cooperate with brands}

Cooperate with brands through advertising (by posting advertisements or product placement of such brands on your channel) and through reviews (by reviewing specific products provided by their producers). This, on the one hand generates revenue, and on the other hand increases your reach and allows you to gain new viewers.

\section{Sell merchandise}

Monetize the popularity and awareness of your channel by selling merchandise that also advertises your channel, such as mugs, T-shirts and other similar gadgets.

\section{Publish in media}

Promote your channel through media relations by inspiring media articles that include information on the existence of your channel, its goals, and content. Ensure a presence in the media, media interest in your activities, and use media articles to increase the awareness of your channel.

\section{Publish books}

Once a critical amount of content has been produced, compile the content most valuable to viewers and publish it in a book, either through self-publishing or via an established publishing house, which will help in promotion. Publishing a book will increase the prestige of your channel and significantly increase the value of your personal brand in the eyes of your viewers.

\section{Meet your viewers}

Participation in mass events is great for networking and an opportunity for YouTube fans to meet their favorites. It can help you increase the awareness of your channel, promote your channel and gain new viewers and subscribers.

\section{Implications and Directions for Future Research}

This work is merely an introduction to the further exploration of a medium as important as YouTube. The author expresses his hope that it will inspire additional research. Such research could, in particular, examine the specific relationship between the time needed to create a professional personal brand and the point at which enough revenue is being generated in order to meet basic needs. Another line of research could investigate the growing interest of companies 
and organizations in personal brand creation, and their acquisition of the revenue earned from these activities. The potential research horizon is broad, and the possible results of further research could significantly influence the understanding of trends and changes in the mechanisms for promoting and distributing content via social media such as YouTube.

From academic point of view, the research examines some relevant questions in field of personal branding. Among them it is important to point out the role of social media in developing personal brand especially activity on YouTube.

From managerial perspective, presented study brings several contributions to marketing professionals. Findings of this study indicate that using of You Tube Channel can lead to successful personal branding effects.

We should remember that this research have some limitations, which can be opportunities for future research. Key limitation of this study is describing social media where the changes take place very rapidly. Secondly, it was only considered limited aspects of developing personal brand.

\section{References}

[1] K. Neher, Social Media Field Guide: Discover the strategies, tactics and tools for successful social media marketing. Boot Camp Digital; USA, 2nd ed, pp. 16, 2013.

[2] Wikipedia, YouTube, [Online]. Available: https://en.wikipedia.org/wiki/YouTube

[3] J. Höller, V. Tsiatsis, C. Mulligan, S. Karnouskos, S. Avesand, D. Boyle, "From Machine-to-Machine to the Internet of Things: Introduction to a New Age of Intelligence," 2014, [Online]. Available: http://www.itbusinessedge.com/cm/community/features/interviews/blog/the-rise-of-the-machine-to-machinesector/?cs=39847

[4] R. Kraut, P. Resnick, S. Kiesler, et al, Regulating Behavior in Online Communities. Cambridge, MA: MIT Press, 2011.

[5] D. Schawbel, Personal Branding 2.0. Kaplan Publishing, pp. 7, 2012.

[6] P. Montoya, T. Vandehey, The Brand called you: Make Your Business Stand Out in a Crowded Marketplace use pre formatted date that complies with legal requirement from media matrix. McGraw-Hill Education; USA, 1st ed, pp. 231, 2008.

[7] Wikipedia, PewDiePie, [Online]. Available: https://en.wikipedia.org/wiki/PewDiePie

[8] PewDiePie Biography, [Online]. Available: http://felixinormation.weebly.com/

[9] Lindsey Stirling, [Online]. Available: http://www.lindseystirling.com/home/

[10] Rhett \& Link, [Online]. Available: http://www.ifc.com/tag/rhett-link-commercial-kings

[11] KSI, [Online]. Available: http://theultimatesidemen.wikia.com/wiki/KSI

[12] Wikipedia, Lilly Singh, [Online]. Available: https://en.wikipedia.org/wiki/Lilly_Singh

[13] Roman Atwood, [Online]. Available: https://romanatwood.com/

[14] Wikipedia, Rosanna Pansino, [Online]. Available: http://smosh.wikia.com/wiki/Rosanna_Pansinov 